\title{
Stray cats are more frequently infected with zoonotic protists than pet cats
}

\author{
Martin Kváćc ${ }^{1,2}$, Lada Hofmannová ${ }^{3}$, Ynes Ortega ${ }^{4}$, Nikola Holubová ${ }^{1,2}$, Michaela Horčičková ${ }^{1,2}$, Marta Kicia $^{5}$, \\ Lenka Hlásková ${ }^{2}$, Dana Květoňová ${ }^{2}$, Bohumil Sak $^{2}$ and John McEvoy ${ }^{6}$
}

\author{
${ }^{1}$ Faculty of Agriculture, University of South Bohemia in České Budějovice, České Budějovice, Czech Republic; \\ ${ }^{2}$ Institute of Parasitology, Biology Centre, Czech Academy of Sciences, České Budějovice, Czech Republic; \\ ${ }^{3}$ Department of Pathology and Parasitology, University of Veterinary and Pharmaceutical Sciences Brno, Brno, Czech Republic; \\ ${ }^{4}$ Center for Food Safety, Department of Food Science \& Technology, University of Georgia, Griffin, USA; \\ ${ }^{5}$ Department of Biology and Medical Parasitology, Wroclaw Medical University, Wroclaw, Poland; \\ ${ }^{6}$ Department of Microbiological Sciences, North Dakota State University, Fargo, ND, USA
}

\begin{abstract}
Faecal samples were collected from cats kept as pets $(\mathrm{n}=120)$ and stray cats $(\mathrm{n}=135)$ in Central Europe (Czech Republic, Poland and Slovakia) and screened for the presence of Cryptosporidium spp., Giardia intestinalis (Kunstler, 1882), Encephalitozoon spp. and Enterocytozoon bieneusi Desportes, Le Charpentier, Galian, Bernard, Cochand-Priollet, Lavergne, Ravisse et Modigliani, 1985 by PCR analysis of the small-subunit of rRNA (Cryptosporidium spp. and G. intestinalis) and ITS (microsporidia) genes. Sequence analysis of targeted genes revealed the presence of $C$. felis Iseki, 1979, G. intestinalis assemblage F, E. cuniculi Levaditi, Nicolau et Schoen, 1923 genotype II, and E. bieneusi genotype D. There was no correlation between the occurrence of detected parasites and sex, presence of diarrhoea or drug treatment (drug containing pyrantel and praziquantel). Compared to pet cats ( $7 \%$ ), stray cats (30\%) were statistically more frequently infected with protist parasites and overall may present a greater risk to human health.
\end{abstract}

Keywords: Cryptosporidium, Giardia, Encephalitozoon, Enterocytozoon bieneusi, antiparasitics, PCR

Since their domestication in the Fertile Crescent at the dawn of human civilisation (Driscoll et al. 2009), cats have risen to become the most popular pets, with a global population estimated at 600 million (McLamb 2013). Cats can host several parasite species that are infectious for humans including nematodes of the genera Toxocara Stiles, 1905 and Ancylostoma Dubini, 1843, the cestodes Dipylidium Leuckart, 1883 and Echinococcus Rudolphi, 1801 and protists of the genera Toxoplasma gondii (Nicolle et Manceaux, 1908), Cryptosporidium Tyzzer, 1910, Giardia Kunstler, 1882, Encephalitozoon Levaditi, Nicolau et Schoen, 1923, and Enterocytozoon Desportes, Le Charpentier, Galian, Bernard, Cochand-Priollet, Lavergne, Ravisse et Modigliani, 1985 (Baneth et al. 2016).

The present study focuses on eukaryotes of the genera Cryptosporidium, Giardia, Encephalitozoon and Enterocytozoon, which have been less well studied in cats, and are associated with disease in immunocompetent and, more frequently, immunocompromised individuals (Thellier and Breton 2008, Ortega and Kváč 2013).

Out of more than 30 species and 100 genotypes of the genus Cryptosporidium, five (C. felis Iseki, 1979, C. parvum
Tyzzer, 1912, C. muris Tyzzer, 1907, C. ryanae Fayer, Santín et Trout, 2008, and Cryptosporidium rat genotype III) have been reported in cats (Sargent et al. 1998, Santín et al. 2006, Yang et al. 2015). Although most cases of human zoonotic cryptosporidiosis are caused by $C$. parvum (see Nichols et al. 2014), C. felis is more prevalent in cats and may be the most likely infectious risk for cat owners (Lucio-Forster et al. 2010, Beser et al. 2015).

Giardia intestinalis (Kunstler, 1882) also has global distribution and is the most common intestinal protist pathogen in humans and animals. Giardia intestinalis consists of seven assemblages with different host specificities (Monis et al. 2003). Among them, assemblages A and B have abroad host range, including humans and cats (i.e. zoonotic genotypes), whereas assemblage $\mathrm{F}$ primarily infects cats (Heyworth 2016).

Most species of the genus Encephalitozoon and genotypes of E. bieneusi Desportes, Le Charpentier, Galian, Bernard, Cochand-Priollet, Lavergne, Ravisse et Modigliani, 1985 infect a broad range of hosts, including pets, livestock, wildlife and humans (Dengjel et al. 2001). Although infections in immunocompetent hosts are usually 
Table 1. Number of samples positive to Cryptosporidium felis Iseki, 1979, Giardia intestinalis (Kunstler, 1882), Encephalitozoon cuniculi Levaditi, Nicolau et Schoen, 1923 and Enterocytozoon bieneusi Desportes, Le Charpentier, Galian, Bernard, Cochand-Priollet, Lavergne, Ravisse et Modigliani, 1985 by PCR in pet and stray cats in the Czech Republic, Poland and Slovakia.

\begin{tabular}{|c|c|c|c|c|c|c|}
\hline Country & $\begin{array}{l}\text { Type of } \\
\text { cats }\end{array}$ & $\begin{array}{l}\text { No. of } \\
\text { cats }\end{array}$ & Cryptosporidium felis & $\begin{array}{l}\text { Giardia intestinalis } \\
\text { assemblage } \mathrm{F}\end{array}$ & $\begin{array}{c}\text { Encephalitozoon cuniculi } \\
\text { genotype II }\end{array}$ & $\begin{array}{c}\text { Eenterocytozoon bieneusi } \\
\text { genotype D }\end{array}$ \\
\hline \multirow{2}{*}{ Czech Republic } & pet & 55 & 1 & 2 & 0 & 0 \\
\hline & stray & 63 & $5^{1}$ & 5 & $3^{1}$ & 3 \\
\hline \multirow{2}{*}{ Slovakia } & pet & 34 & 0 & 3 & 1 & 0 \\
\hline & stray & 39 & 3 & 3 & $2^{2}$ & $5^{2}$ \\
\hline \multirow{2}{*}{ Poland } & pet & 31 & 0 & 1 & 0 & 0 \\
\hline & stray & 33 & 2 & 2 & $3^{3,4}$ & $4^{3,4}$ \\
\hline
\end{tabular}

1-4 upper indices indicate an animal with coinfection.

inapparent, they can cause disseminated infection manifesting serious health problems (Mathis et al. 2005).

Cats have a tendency towards independence and frequently spend periods outdoors, where they can come into contact with infected animals and contaminated food and water. We hypothesised that stray cats, which spend longer periods outside, are more frequently infected with zoonotic protists than pet cats and may represent a human health risk during the rehoming process. We undertook the present study to describe the presence of Cryptosporidium spp., G. intestinalis, and microsporidia of the genera Encephalitozoon and Enterocytozoon in pet and stray cats. Associations with antiparasitic treatment, sex of the animal and the presence of diarrhoea were also examined.

A total of 255 faecal samples were collected from pet $(n=120)$ and stray $(n=135)$ cats. Pet cats were defined as those living with people in their homes and under periodic veterinary control. Stray cats were defined as those found roaming freely without human supervision around human settlements and subsequently kept in shelters in the Czech Republic, Poland or Slovak Republic. Faecal samples from pet and stray cats were collected by cat owners and shelter employees, respectively. Each sample was processed as a mixture of three samples collected within three days with a one-day pause between collections. All examined animals were older than one year. Each cat was sampled once and a faecal sample was individually placed in a plastic dish without fixation, stored in the dark at $4{ }^{\circ} \mathrm{C}$ before examination for parasites. Consistency of faeces (presence of diarrhoea) and the known treatment history of the animal were noted at the time of sampling.

Genomic DNA was extracted from $200 \mathrm{mg}$ of each faecal sample. A nested PCR approach was used to amplify a region of the internal transcribed spacer (ITS) of E. bieneusi (see Buckholt et al. 2002) or Encephalitozoon spp. (see Didier et al. 1995, Katzwinkel-Wladarsch et al. 1996) and the small ribosomal subunit rRNA gene (18S rRNA) of Cryptosporidium spp. (see Alves et al. 2003) and Giardia spp. (see Read et al. 2002). DNA of C. suis Ryan, Monis, Enemark, Sulaiman, Samarasinghe, Read, Buddle, Robertson, Zhou, Thompson et Xiao, 2004, G. intestinalis assemblage E, E. cuniculi genotype III, and E. bieneusi genotype $\mathrm{CZ3}$, respectively, was used as positive control.

Purified secondary PCR products (GenElute Gel Extraction Kit, Sigma, St. Louis, MO, USA) were sequenced twice in both directions with secondary primers using a BigDye Terminator v3.1 cycle sequencing kit in an ABI Prism 3130 genetic analyser (Applied Biosystems, Carlsbad, CA, USA). The nucleotide sequences of each gene obtained in this study were aligned with previously published sequences saved in GenBank using the MAFFT version 7 online server (http://mafft.cbrc.jp/alignment/server/). Phylogenetic trees with bootstrap support were inferred by maximum likelihood using the MEGA6 software.

Out of 255 cats sampled in Central Europe, 11, 16, 9 and 12 were positive for DNA of species of Cryptosporidium, Giardia, Encephalitozoon, and E. bieneusi, respectively.

A Maximum Likelihood tree constructed from partial sequences of $18 \mathrm{~S}$ rDNA of species of Cryptosporidium and Giardia showed the presence of $C$. felis (identical to GenBank Accession no. AF112575) and G. intestinalis assemblage F (identical to AF199444), respectively. Sequence analyses of the ITS of microsporidia revealed the presence of E. cuniculi genotype II (identical to GQ422153) and E. bieneusi genotype D (identical to KF383393; phylogenies not shown). Cryptosporidium felis was found in one pet and 10 stray cats. Giardia intestinalis was found in six pet and ten stray cats. Encephalitozoon cuniculi Levaditi, Nicolau et Schoen, 1923 was detected in one pet and eight stray cats. Enterocytoozoon bieneusi was not found in pet cats but was detected in 12 stray cats (Table 1).

Most positive animals (40 out of 44) were infected with just one of the parasite species examined, three were co-infected with E. bieneusi and E. cuniculi, and one was co-infected with $C$. felis and E. cuniculi. Multiple species infections were detected only in stray cats (Table 1). Statistical analyses on the entire dataset revealed significantly higher prevalence of each parasite in stray cats than in pet cats (Table 2). There was no association between sex of the animal, presence of diarrhoea or drug treatment (drug containing pyrantel and praziquintel) and the occurrence of C. felis, G. intestinalis, E. cuniculi or E. bieneusi $(\mathrm{p}$-value $=0.0637-0.7118$; Table 2$)$.

In the present study, PCR and sequence analysis were used to detect species and genotypes of Cryptosporidium, Giardia, Encephalitozoon, and E. bieneusi in cats from Central Europe. All Cryptosporidium-positive cats were shedding C. felis, which is consistent with the reported dominance of this species in domestic cats, whereas other species and genotypes are reported less frequently (Santín et al. 2006, Palmer et al. 2008, Xu et al. 2016). There are many reports of cryptosporidiosis of cats, with a prevalence 
Table 2. Factors examined for association with shedding of (oo)cysts of Cryptosporidium felis Iseki, 1979 and Giardia intestinalis (Kunstler, 1882) and spores of Encephalitozoon cuniculi Levaditi, Nicolau et Schoen, 1923 and Enterocytozoon bieneusi Desportes, Le Charpentier, Galian, Bernard, Cochand-Priollet, Lavergne, Ravisse et Modigliani, 1985 in cats.

\begin{tabular}{|c|c|c|c|c|c|c|c|c|c|c|c|c|c|}
\hline \multirow[t]{2}{*}{ Factor } & \multirow{2}{*}{$\begin{array}{c}\text { No. of } \\
\text { animals }\end{array}$} & \multicolumn{3}{|c|}{ Cryptosporidium felis } & \multicolumn{3}{|c|}{ Giardia intestinalis } & \multicolumn{3}{|c|}{ Encephalitozoon cuniculi } & \multicolumn{3}{|c|}{ Enterocytozoon bieneusi } \\
\hline & & $\begin{array}{c}\text { No. of } \\
\text { positive }\end{array}$ & $\chi^{2}$ & P-value & $\begin{array}{c}\text { No. of } \\
\text { positive }\end{array}$ & $\chi^{2}$ & P-value & $\begin{array}{c}\text { No. of } \\
\text { positive }\end{array}$ & $\chi^{2}$ & P-value & $\begin{array}{c}\text { No. of } \\
\text { positive }\end{array}$ & $\chi^{2}$ & P-value \\
\hline \multicolumn{14}{|l|}{ Housing } \\
\hline pet cat & 120 & 1 & \multirow{2}{*}{5.15} & \multirow{2}{*}{0.0232} & 6 & \multirow{2}{*}{0.28} & \multirow{2}{*}{0.5943} & 1 & \multirow{2}{*}{3.45} & \multirow{2}{*}{0.0629} & 0 & \multirow{2}{*}{9.29} & \multirow{2}{*}{0.0020} \\
\hline stray cat & 135 & 10 & & & 10 & & & 8 & & & 12 & & \\
\hline \multicolumn{14}{|l|}{ Sex } \\
\hline male & 143 & 5 & \multirow{2}{*}{1.72} & \multirow{2}{*}{0.6779} & 6 & \multirow{2}{*}{2.39} & \multirow{2}{*}{0.1219} & 6 & \multirow{2}{*}{0.33} & \multirow{2}{*}{0.5681} & 7 & \multirow{2}{*}{0.02} & \multirow{2}{*}{0.8912} \\
\hline female & 112 & 6 & & & 10 & & & 3 & & & 5 & & \\
\hline \multicolumn{14}{|l|}{ Faecal consistency } \\
\hline diarrhoea & 23 & 2 & \multirow{2}{*}{0.29} & \multirow{2}{*}{0.5847} & 4 & \multirow{2}{*}{3.43} & \multirow{2}{*}{0.0637} & 1 & \multirow{2}{*}{0.14} & \multirow{2}{*}{0.7118} & 1 & \multirow{2}{*}{0.18} & \multirow{2}{*}{0.6664} \\
\hline solid specimen & 232 & 9 & & & 12 & & & 8 & & & 11 & & \\
\hline \multicolumn{14}{|l|}{ Treatment } \\
\hline yes & 216 & 8 & \multirow{2}{*}{0.49} & 04838 & 11 & 216 & 01408 & 8 & 001 & 09072 & 9 & 029 & 05849 \\
\hline no & 39 & 3 & & & 5 & 2.10 & 0.1400 & 1 & 0.01 & 0.9012 & 3 & 0.29 & 0.5049 \\
\hline
\end{tabular}

ranging from 1 to $25 \%$ (e.g. Rambozzi et al. 2007, Yang et al. 2015), but few studies have compared the occurrence of cryptosporidia in pet and stray cats. Similarly to Yang et al. (2015) and Xu et al. (2016) we found to be more frequently present in stray cats $(8 \%)$ than pet cats $(1 \%)$. The prevalence of $G$. intestinalis in cats $(6 \%)$ was similar to that in Columbia, Italy and the United States (3-11\%; Hill et al. 2000, Spain et al. 2001, Santín et al. 2006), but lower than prevalence found in Australia (80\%; McGlade et al. 2003). In accordance with Paoletti et al. (2011), we found a higher occurrence of this parasite in stray cats than pet cats.

Similarly, E. cuniculi and E. bieneusi were more prevalent in stray cats than in pet cats. The prevalence of microsporidia was low in stray and pet cats, which corresponds to previous findings (Santín et al. 2006, Xu et al. 2016). Encephalitozoon cuniculi was the only species of Encephalitozoon found in cats in the present study and it is the dominant species reported in other studies on cats (Hsu et al. 2011, Piekarska et al. 2017), with only one report of another species, E. intestinalis, in a cat from Brazil (Velasquez et al. 2012). Although Encephalitozoon spp. can cause severe generalised encephalitozoonosis or cataracts and uveitis in cats, these zoonotic agents are probably relatively rare, as evidenced by low seroprevalence $(2 \%)$ in healthy cats (Buyukmihci et al. 1977, Hsu et al. 2011, Rebel-Bauder et al. 2011). Whereas 13 genotypes of E. bieneusi have been reported in cats (Karim et al. 2014), we detected only genotype D, which is one of the most frequently reported genotypes (Santín et al. 2006, $\mathrm{Xu}$ et al. 2016). In contrast to previous surveys (Dengjel et al. 2001, Xu et al. 2016), we did not find E. bieneusi in pet cats.

Similar to other studies (Santín et al. 2006, de Lucio et al. 2017), only cat-specific $G$. intestinalis assemblage F was found in the present study, suggesting that cats do not represent a risk in the transmission of $G$. intestinalis to humans. The zoonotic potential of feline cryptosporidiosis is considered to be medium and the zoonotic transmission of C. felis between cat and humans in a household has been reported (Beser et al. 2015). About 100 cases of $C$. felis have been reported in humans to date, with the majority reported in immunocompromised individuals (Caccio and Putignani 2014). Both E. cuniculi genotype II and E. bieneusi genotype D have a broad host specificity and have been reported in humans. Although the sources of microsporidia infecting humans are not well known, there is evidence of zoonotic transmission (Dengjel et al. 2001) and cats should be considered a potential source (Mathis et al. 2005).

Although species of Cryptosporidium, Giardia, Encephalitozoon and Enterocytozoon occur frequently in populations of domestic, captive and wild animals, coinfections with parasites of two or more of these genera had a low prevalence in the present study, which is consistent with previous findings (Mynařová et al. 2016, Peng et al. 2016). This may be explained by animals shedding parasites intermittently, which may be missed by the sampling approach employed (Sak et al. 2010).

Treatment of cats with drugs containing pyrantel and praziquantel had no effect on the prevalence of protist infections, which is unsurprising considering that these drugs were designed to treat helminth infections. Previous studies have shown that 3-5 doses of Drontal, which contains pyrantel, praziquantel and febantel, cleared infection with $G$. intestinalis in dogs (Barr et al. 1998, Montoya et al. 2008); however, Payne et al. (2002) found that dogs treated with Drontal for three consecutive days did not clear giardiasis. Similarly to the present study, Pavlásek (2005) reported that praziquantel and pyrantel were not effective at treating Cryptosporidium infection in cats.

Due to the lack of clinical signs, the parasites detected in the present study are unlikely to be suspected during routine health examinations by veterinarians. Therefore, people who come into contact with cats, particularly stray cats, may be unaware of the potential health risk.

Acknowledgements. The authors thank the veterinarians and owners of cats for their help with material sampling. This study was funded by the Czech Science Foundation (project No. 1501090S), Institute of Parasitology (RVO: 60077344) and the Grant Agency of the University of South Bohemia (project No. 002/2016/Z). 


\section{REFERENCES}

Alves M., Xiao L.H., Sulaiman I., Lal A.A., Matos O., AnTUNES F. 2003: Subgenotype analysis of Cryptosporidium isolates from humans, cattle, and zoo ruminants in Portugal. J. Clin. Microbiol. 41: 2744-2747.

Baneth G., Thamsborg S.M., Otranto D., Guillot J., Blaga R., Deplazes P., Solano-Gallego L. 2016: Major parasitic zoonoses associated with dogs and cats in Europe. J. Comp. Pathol. 155: S54-74.

Barr S.C., Bowman D.D., Frongillo M.F., Joseph S.L. 1998: Efficacy of a drug combination of praziquantel, pyrantel pamoate, and febantel against giardiasis in dogs. Am. J. Vet. Res. 59: 1134-1136.

Beser J., Toresson L., Eitrem R., Troell K., Winiecka-KrusNell J., LebBad M. 2015: Possible zoonotic transmission of Cryptosporidium felis in a household. Infect. Ecol. Epidemiol. 5: 28463.

Buckholt M.A., Lee J.H., Tzipori S. 2002: Prevalence of Enterocytozoon bieneusi in swine: an 18-month survey at a slaughterhouse in Massachusetts. Appl. Environ. Microbiol. 68: 25952599.

Buyukmihci N., Bellhorn R.W., Hunziker J., Clinton J. 1977: Encephalitozoon (Nosema) infection of the cornea in a cat. J. Am. Vet. Med. Assoc. 171: 355-357.

Caccio S.M., Putignani L. 2014: Epidemiology of human cryptosporidiosis. In: S.M. Cacciò and G. Widmer (Eds.), Cryptosporidium: Parasite and Disease. Springer, Wien, pp. 43-80.

Dengjel B., Zahler M., Hermanns W., Heinritzi K., Spillmann T., Thomschke A., Loscher T., Gothe R., Rinder H. 2001: Zoonotic potential of Enterocytozoon bieneusi. J. Clin. Microbiol. 39: 4495-4499.

Didier E.S., Vossbrinck C.R., Baker M.D., Rogers L.B., BertucCi D.C., Shadduck J.A. 1995: Identification and characterization of three Encephalitozoon cuniculi strains. Parasitology 111: 411-421.

Driscoll C.A., Macdonald D.W., O’Brien S.J. 2009: From wild animals to domestic pets, an evolutionary view of domestication. Proc. Natl. Acad. Sci. USA 106, Suppl 1: 9971-9978.

Heyworth M.F. 2016: Giardia duodenalis genetic assemblages and hosts. Parasite 23: 13.

Hill S.L., Cheney J.M., Taton-Allen G.F., Reif J.S., Bruns C., Lappin M.R. 2000: Prevalence of enteric zoonotic organisms in cats. J. Am. Vet. Med. Assoc. 216: 687-692.

Hsu V., Grant D.C., Zajac A.M., Witonsky S.G., Lindsay D.S. 2011: Prevalence of IgG antibodies to Encephalitozoon cuniculi and Toxoplasma gondii in cats with and without chronic kidney disease from Virginia. Vet. Parasitol. 176: 23-26.

Karim M.R., Dong H., Yu F., Jian F., Zhang L., Wang R., Zhang S., Rume F.I., Ning C., Xiao L. 2014: Genetic diversity in Enterocytozoon bieneusi isolates from dogs and cats in China: host specificity and public health implications. J. Clin. Microbiol. 52: 3297-3302.

Katzwinkel-Wladarsch S., Lieb M., Helse W., Loscher T., RINDER H. 1996: Direct amplification and species determination of microsporidian DNA from stool specimens. Trop. Med. Int. Hlth 1: 373-378.

de Lucio A., Bailo B., Aguilera M., Cardona G.A., FernanDez-Crespo J.C., Carmena D. 2017: No molecular epidemiological evidence supporting household transmission of zoonotic Giardia duodenalis and Cryptosporidium spp. from pet dogs and cats in the province of Alava, Northern Spain. Acta Trop. 170: $48-56$.

Lucio-Forster A., Griffiths J.K., Cama V.A., Xiao L.H., Bowman D.D. 2010: Minimal zoonotic risk of cryptosporidiosis from pet dogs and cats. Trends Parasitol. 26: 174-179.

Mathis A., Weber R., Deplazes P. 2005: Zoonotic potential of the microsporidia. Clin. Microbiol. Rev. 18: 423-445.
McGlade T.R., Robertson I.D., Elliot A.D., Read C., THOMPSON R.C.A. 2003: Gastrointestinal parasites of domestic cats in Perth, Western Australia. Vet. Parasitol. 117: 251-262.

McLamb E. 2013. Real ecology, born in the streets: the global impact of feral cat, http://www.ecology.com/2013/08/27/global-impact-feral-cats/.

Monis P.T., Andrews R.H., Mayrhofer G., Ey P.L. 2003: Genetic diversity within the morphological species Giardia intestinalis and its relationship to host origin. Infect. Genet. Evol. 3: $29-38$.

Montoya A., Dado D., Mateo M., Espinosa C., Miro G. 2008 Efficacy of Drontal (R) Flavour Plus (50 mg praziquantel, $144 \mathrm{mg}$ pyrantel embonate, $150 \mathrm{mg}$ febantel per tablet) against Giardia sp. in naturally infected dogs. Parasitol. Res. 103: 1141-1144.

Mynařová A., Foitová I., Kváč M., Květoňová D., Rost M., Morrogh-Bernard H., Nurcahyo W., Nguyen C., SupriYADI S., SAK B. 2016: Prevalence of Cryptosporidium spp., Enterocytozoon bieneusi, Encephalitozoon spp. and Giardia intestinalis in wild, semi-wild and captive orangutans (Pongo abelii and Pongo pygmaeus) on Sumatra and Borneo, Indonesia. PLoS ONE 11: e0152771.

Nichols G.L., Chalmers R.M., Hadfield S.J. 2014: Molecular epidemiology of human cryptosporidiosis. In: S.M. Cacciò and G. Widmer (Eds.), Cryptosporidium: Parasite and Disease. Springer, Wien, pp. 237-326.

Ortega Y.R., Kváč M. 2013: Foodborne protozoa. In: R.G. Labbé and S. García (Eds.), Guide to Foodborne Pathogens. John Wiley \& Sons, Oxford, pp. 303-316.

Palmer C.S., Traub R.J., Robertson I.D., Devlin G., Rees R., Thоmpson R.C.A. 2008: Determining the zoonotic significance of Giardia and Cryptosporidium in Australian dogs and cats. Vet. Parasitol. 154: 142-147.

Paoletti B., Otranto D., Weigl S., Giangaspero A., Di CeSare A., Traversa D. 2011: Prevalence and genetic characterization of Giardia and Cryptosporidium in cats from Italy. Res. Vet. Sci. 91: 397-399.

PAVLÁSEK I. 2005: [First detection of oocysts morphometrically similar to Cryptosporidium muris and C. andersoni in cat.] Veterinářství 55: 480-483. (In Czech.)

Payne P.A., Ridley R.K., Dryden M.W., Bathgate C., MilLiken G.A., Stewart P.W. 2002: Efficacy of a combination febantel-praziquantel-pyrantel product, with or without vaccination with a commercial Giardia vaccine, for treatment of dogs with naturally occurring giardiasis. J. Am. Vet. Med. Assoc. 220: 330-333.

Peng X.Q., Tian G.R., Ren G.J., Yu Z.Q., LoK J.B., Zhang L.X., Wang X.T., Song J.K., Zhao G.H. 2016: Infection rate of Giardia duodenalis, Cryptosporidium spp. and Enterocytozoon bieneusi in cashmere, dairy and meat goats in China. Infect. Genet. Evol. 41: 26-31.

Piekarska J., Kicia M., Wesolowska M., Kopacz Z., Gorczy Kowski M., Szczepankiewicz B., Kváč M., SaK B. 2017: Zoonotic microsporidia in dogs and cats in Poland. Vet. Parasitol. 246: 108-111.

Rambozzi L., Menzano A., Mannelli A., Romano S., Isaia M.C. 2007: Prevalence of cryptosporidian infection in cats in Turin and analysis of risk factors. J. Feline Med. Surg. 9: 392 396.

Read C., Walters J., Robertson I.D., Thompson R.C.A. 2002: Correlation between genotype of Giardia duodenalis and diarrhoea. Int. J. Parasitol. 32: 229-231.

Rebel-Bauder B., Leschnik M., Maderner A., Url A. 2011: Generalized encephalitozoonosis in a young kitten with cerebellar hypoplasia. J. Comp. Pathol. 145: 126-131.

SaK B., KašıčKová D., Kváč M., Květoňová D., Ditrich O. 2010: Microsporidia in exotic birds: intermittent spore excretion 
of Encephalitozoon spp. in naturally infected budgerigars (Melopsittacus undulatus). Vet. Parasitol. 168: 196-200.

Santín M., Trout J.M., Vecino J.A., Dubey J.P., Fayer R. 2006: Cryptosporidium, Giardia and Enterocytozoon bieneusi in cats from Bogota (Colombia) and genotyping of isolates. Vet. Parasitol. 141: 334-339.

Sargent K.D., Morgan U.M., Elliot A., Thompson R.C.A. 1998: Morphological and genetic characterisation of Cryptosporidium oocysts from domestic cats. Vet. Parasitol. 77: 221227.

Spain C.V., Scarlett J.M., Wade S.E., McDonough P. 2001: Prevalence of enteric zoonotic agents in cats less than 1 year old in central New York State. J. Vet. Intern. Med. 15: 33-38.
Thellier M., Breton J. 2008: Enterocytozoon bieneusi in human and animals, focus on laboratory identification and molecular epidemiology. Parasite 15: 349-358.

Velasquez J.N., Chertcoff A.V., Etchart C., di Risio C., Sodre F.C., Cucher M.A., Carnevale S. 2012: First case report of infection caused by Encephalitozoon intestinalis in a domestic cat and a patient with AIDS. Vet. Parasitol. 190: 583-586.

Xu H., Jin Y., Wu W., Li P., Wang L., Li N., Feng Y., XiaO L. 2016: Genotypes of Cryptosporidium spp., Enterocytozoon bieneusi and Giardia duodenalis in dogs and cats in Shanghai, China. Parasit. Vectors 9: 121.

YAng R.C., Ying J.L.J., Monis P., Ryan U. 2015: Molecular characterisation of Cryptosporidium and Giardia in cats (Felis catus) in Western Australia. Exp. Parasitol. 155: 13-18. 